\title{
Effects Of Information Education And Communication (IEC) - Based Intervention On Knowledge And Attitude Towards Cervical Cancer Preventionamong Teachers In Taraba State
}

\author{
Rosethe Rimande-Joel \\ Georgy 0. Obiechina
}

\begin{abstract}
The Study Examined the Effect of Information Education and Communication (IEC)Based Intervention on Knowledge and Attitude toward Cervical Cancer Prevention among Primary School Teachers in Jalingo, Taraba State. Pre-test and post-test quasi experimental design was adopted for the study. The study was guided by two specific objectives, two research questions and two null hypotheses tested at 0.05 alpha level. Population for the study consisted of (998) primary school female teachers in Jalingo. Multistage sampling procedure was used for recruiting (224) respondents; (111) for experimental group and (113) for the control group. Self-structured questionnaire titled knowledge and Attitude towards Cervical Cancer Prevention (KACCP) was used for data collection. Descriptive statistic of percentage and mean was used to analyze the demographic data and research questions, respectively; while inferential statistics of Analysis of Covariance (ANCOVA) was used to test the hypotheses at 0.05 alpha level. The compared result from the pretest and posttest showed that Information Education and Communication -Based intervention significantly increased knowledge, $\left(F_{1}\right.$, $213=65.626, p<.05)$ and positive attitude $\left(F_{1}, 213=368.367, p<.05\right)$ toward cervical cancer prevention. Based on the findings of the study it was recommended that periodic IEC-based programmes on cervical cancer should be organized for teachers and they be encouraged to step down the knowledge to pupils in order to spread knowledge and influence attitude and practice. Nigerian Ministry of health should develop and implement policy for IEC-based health education on cervical cancer prevention to be given in all maternal and child health clinics on each visit. And cervical cancer screening should be part of the routine examination.
\end{abstract}

Key Words: Information Education and Communication, Knowledge, Attitude, Cervical Cancer, Screening, Prevention, Teachers.

\section{INTRODUCTION}

Cervical Cancer is cancer of the cervix found only among women. It is a preventable communicable disease. It's been noted as the most common cancer in women (Nwankwo, Aniebue, Aguwa, Anarado, Agunwah, 2011,) living in the low and middle-income countries (Denny, Herrero, Levin, \& Kim, 2015). Worldwide it is the fourth most common cancer among women and found to be the leading cause of deaths in some third world countries (World Health Organization - WHO, 2015 and WHO, 2018). In Sub-Saharan Africa and Nigeria in particular, cervical cancer is the second most common among women cancer (WHO, 2014).

Worldwide about 1.4 million women are diagnosed with cervical cancer (GLOBOCAN, 2012 and WHO, 2013). Statistics shows that one in ten women is diagnosed with cervical cancer; and in every two minutes, a woman loses her life as a result of cervical cancer (American Cancer Society, 2013). A total of 46,000 women aged 15-49 lose their lives to cervical cancer annually; accounting for $15 \%$ of all gynecological cancers in unindustrialized countries (Forouzanfar, 
2011). Globally estimated new cases of cervical cancer is put at 570,000 as of 2018 representing $6.6 \%$ of all gynecological cancers with mortality rate of $7.5 \%$. Unfortunately the highest death rate is recorded in low- and middle-income countries; approximated to $90 \%$ (WHO, 2019).Cervical cancer is a prevailing issue in the developing countries especially Africa.

WHO in 2010, estimated that Africa alone will have about 75,000 diagnosed women with cervical cancer; and will record beyond 50,000 deaths from the disease (WHO, 2015). Research findings have shown undeniable evidence that sub Saharan Africa has about $80 \%$ of the world total cervical cancer incidence, the same diagnosed at advanced stages of the disease (Horo, Jaquet, Ekouevi, et al; 2012 and Nwankwo, Aniebue, Aguwa, Anarado, and Agunwah, 2011).

In Nigeria, cervical cancer is the commonest gynecological cancer and a leading cause of cancer death among women. (Sule \& Ochicha, 2017). Oguntayo (2011) cited in Akintayo, \& Bello, (2015), posited that in northern Nigeria cervical cancer is the leading cause of gynecological cancers; responsible for $65.7 \%$ of all gynecological cancers in the country. The work also reported that by 2025 , new diagnoses will rise to 22,914 and the mortality rate put at 15,251 . While the estimated National Age standardized incidence rate for cervical cancer in Nigeria is put at 33.0 cases per 100,000 women per year. (Abiodun, Fatungase, Olu-Abiodun, IdowuAjiboye, \& Awosile 2013).

Human papilloma virus (HPV) is known to be an important factor in cervical cancer occurrences. Almost $99.7 \%$ of diagnosed cervical cancers have been connected to genital HPV infections. Factors contributing to transmission and persistence of HPV infection are: early exposure to sex, multiples sexual partners, infection with other sexually transmitted infection, early childbirth, and longtime use of contraceptives pills, weak immune system, smoking, and low socio-economic status (Gamage, 2017). Cervical cancer is one of the most easily preventable gynecological cancers. However, lack of knowledge about the disease and risk factors and negative attitude are capable of affecting decision to uptake cervical cancer screening (WHO, 2013).

Due to the ever increasing health burden of cervical cancer especially in developing countries diverse measures such as health education, screening, vaccination, Information, Communication Technology and treatment have been employed to combat the increase in diagnosing cervical cancer (McGraw, \& Ferrante, 2014 and Gatune, \& Nyamongo, 2005). The industrialized countries have witnessed a significant reduction in cervical cancer due to access information on the disease management (Hanisch, Gustat, Hagensee, Baena, Salazar, et al, 2008).

Evidence abound that simple, accurate and consistent information about any phenomenon is capable of building an individual's capacity and placing him/her at advantageous position to deal with it. Thus the individual is better placed to confront the situation and is able to prevent it or have control over future challenge. Practice has revealed that the problem of public health improvement is intimately connected to the information and education of the public so as to raise their knowledge and awareness (Labonté \& Schrecker, 2007). Lack of accurate and simple information about prevention is a hindrance to women access to cancer screening services (Bethune \& Lewis, 2009). If prompt measures are not employed to improve women knowledge, attitude toward cervical cancer prevention; diagnoses of new cases will be on the increase.

Therefore the deployment of multi-channel means of communicating health messages is the surest way to increase knowledge and change attitude positively. Hence the need for 
purposeful Information, Education and Communication (IEC) - based health education in order to build their capacity and reinforce partial knowledge and positively influence change in attitude toward prevention practice.

Information, Education and Communication is making great impact in health care system in the area of prevention and treatment. Information, Education and Communication has been recognized as one of the practicable and cost-effective approaches that can be used in addressing wide range determinants of health, risk factors, building trust and commitment, nurturing community participation, and empowerment in the direction of development and implementation of health initiatives (Osumanu, 2008). Gupta Bhardwaj and shaiju (2013) described Information Education and Communication as an "approach which attempts to change or reinforce a set of behaviour in a target audience regarding a specific problem in a predefined period of time". IEC-Based health Education can simply be refer to as an approach that combination audio, visual audio-visual material and health education to provide and reinforce knowledge to bring about the desire change in attitude and development of positive health care seeking behaviour.

\section{Aim and Objectives}

The aim of the paper is to investigate the effect of IEC-based intervention on Knowledge and Attitude toward cervical cancer prevention among female primary school teachers in Jalingo. The specific research objectives are to:

1. determine the effect of IEC- based intervention on knowledge of cervical cancer among the teachers.

2. ascertain the effect of IEC- based intervention on attitude of the teachers toward cervical cancer screening.

\section{Research Questions}

Two research questions guided the study

1. What is the effect of IEC- based intervention on knowledge of cervical cancer screening among teachers in Jalingo?

2. What is the effect of IEC- based intervention on attitude of teachers the toward cervical cancer screening?

\section{Hypotheses}

These null hypotheses were tested at 0.05 alpha level.

1. IEC-based intervention has no significant effect on knowledge of cervical cancer screening among teachers in Jalingo.

2. IEC-based intervention has no significant effect on the attitude of the teachers towards cervical cancer screening.

\section{METHODOLOGY}

The research design adopted for this study was a Pretest and posttest Quasi-experimental design. One group was given IEC materials while the control group only received verbal message. Population of the study consisted of nine hundred and ninety eight (998) female teachers in 48 primary schools within Jalingo Local government area of Taraba State. The sample comprised of two hundred and twenty four (224) female primary school teachers selected using multistage sampling procedure to obtain the sample of 111 and 113 for experimental and control groups respectively. The instrument for data collection was a 62 items Self structured questionnaire titled knowledge, Attitude and Practice of cervical Cancer prevention (KAPCCP) and self-developed intervention programme. The instrument was validated by two experts in the department of human Kinetics and health education, University 
Rimande-Joel, R., \& Obiechina, G. O. (2020). Effects Of Information Education And Communication (IEC) -Based Intervention On Knowledge And Attitude Towards Cervical Cancer Preventionamong Teachers In Taraba State. Advances in Social Sciences Research Journal, 7(1) 421-429.

of Port Harcourt. The reliability of the instrument was determined using Cronbach Alpha. The knowledge subscale had a coefficient of 0.80 whereas the attitude subscale had a coefficient of 0.96. The coefficients were high thus, the instruments considered reliable for the study. Data Analysis was done using Statistical Package for Social Sciences (SPSS 16). Descriptive statistic of percentage and mean was used to analyse the research questions; while inferential statistics of and Analysis of Covariance (ANCOVA) was used to test the hypotheses at 0.05 alpha level.

Ethical Approval: The study ethical approval was obtained from the research and ethic committee of University of Port Harcourt. And the respondent consent was obtained assuring them of confidentiality.

\section{ANALYSIS OF FINDINGS AND DISCUSSION}

Research question 1: What is the effect of IEC- based intervention on knowledge of cervical cancer prevention among teachers in Jalingo?

Table 4.1.2: Summary of Frequency and percentage responses on the effect of IEC- based intervention on knowledge of cervical cancer prevention among teachers in Jalingo?

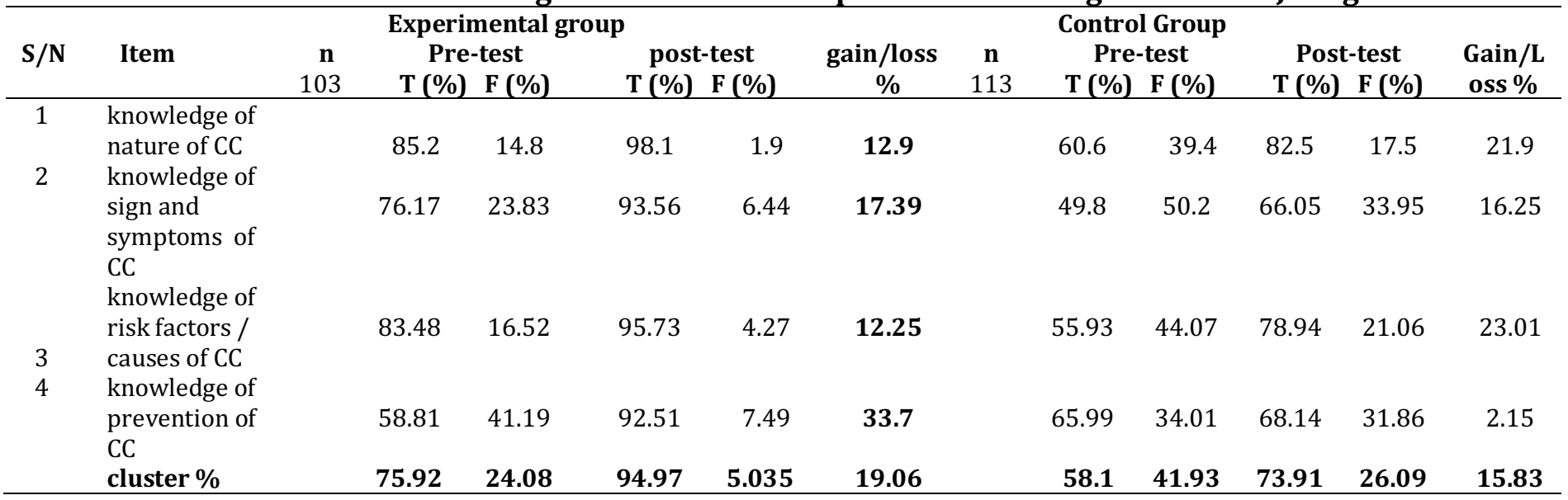

Result from the table 1 revealed that respondents from the experimental group had a pretest cluster percentage of $75.92 \%$ on knowledge items whereas that of the counterpart in Control group obtained a cluster percentage of $58.1 \%$. this revealed a difference of $17.82 \%$ in the pretest knowledge score to the advantage of the experimental group. Also the cluster persentage in the post-test in the experimental group was $94.97 \%$ while that of the control group is $73.91 \%$ the difference in percentage between the groups is $21.06 \%$ in favoured of the experimental group. the implication is that IEC-based intervention has effect on knowledge of cervical cancer screening among teachers. The table aslo showed gains of each item after post test as follows: knowledge of nature of CC (12.9\%), knowledge of sign and symptoms of CC $(17.39 \%)$, knowledge of risk factors / causes of CC (12.25\%) and knowledge of prevention of CC $(33.7 \%)$ compare to that of their counterpart which showed $21.1 \%, 16.25,23.01 \%, 2.15 \%$ respectively

Research question 2: What is the effect of IEC- based intervention on attitude of the teachers toward cervical cancer prevention? 
Table 2 Summary of mean rating on attitude of the teachers toward cervical cancer prevention in the experimental and control groups

\begin{tabular}{|c|c|c|c|c|c|c|c|c|c|c|c|}
\hline \multirow[b]{3}{*}{ SN } & \multirow[b]{3}{*}{ Attitude } & \multicolumn{4}{|c|}{ Experimental Group, N=103 } & \multicolumn{5}{|c|}{ Control Group, N=113 } & \multirow[b]{3}{*}{$\begin{array}{l}\text { Gain/ } \\
\text { Loss }\end{array}$} \\
\hline & & \multicolumn{2}{|c|}{ Pretest } & \multicolumn{2}{|c|}{ Posttest } & \multirow[b]{2}{*}{$\begin{array}{l}\text { Gain/ } \\
\text { Loss }\end{array}$} & \multicolumn{2}{|c|}{ Pretest } & \multicolumn{2}{|c|}{ Posttest } & \\
\hline & & Mean & SD & Mean & SD & & Mean & SD & Mean & SD & \\
\hline 1 & $\begin{array}{l}\text { I am healthy and cannot develop } \\
\text { cervical cancer }\end{array}$ & 1.87 & 0.93 & 2.72 & 1.01 & 0.84 & 2.19 & 1.11 & 1.74 & 0.99 & -0.45 \\
\hline 2 & $\begin{array}{l}\text { Cervical cancer screening is } \\
\text { unnecessary if the person has no } \\
\text { signs or symptoms }\end{array}$ & 1.86 & 0.91 & 2.79 & 1.09 & 0.92 & 1.78 & 0.95 & 1.41 & 0.61 & -0.37 \\
\hline 3 & $\begin{array}{l}\text { I feel that Cervical cancer is disease } \\
\text { of the elderly only }\end{array}$ & 1.54 & 0.61 & 2.95 & 1.17 & 1.41 & 1.77 & 1.02 & 1.32 & 0.64 & -0.45 \\
\hline 4 & $\begin{array}{l}\text { One's sexual life style does not } \\
\text { predispose one to developing } \\
\text { cervical cancer }\end{array}$ & 1.98 & 0.78 & 3.00 & 0.95 & 1.02 & 2.04 & 0.99 & 1.28 & 0.53 & -0.75 \\
\hline 5 & $\begin{array}{l}\text { Cervical cancer is a punishment } \\
\text { from the gods }\end{array}$ & 1.65 & 0.92 & 2.63 & 1.09 & 0.98 & 1.49 & 0.86 & 1.60 & 0.49 & 0.12 \\
\hline 6 & $\begin{array}{l}\text { Cervical cancer is caused by } \\
\text { witches and wizards }\end{array}$ & 1.25 & 0.44 & 2.62 & 1.07 & 1.37 & 1.43 & 0.85 & 1.38 & 0.63 & -0.05 \\
\hline 7 & $\begin{array}{l}\text { I believe it is shameful and } \\
\text { embarrassing to undergo cervical } \\
\text { cancer screening (pap test) }\end{array}$ & 1.40 & 0.55 & 3.08 & 1.04 & 1.68 & 1.92 & 1.14 & 1.70 & 0.48 & -0.22 \\
\hline 8 & $\begin{array}{l}\text { Going for screening is lack of faith } \\
\text { and belief in God }\end{array}$ & 1.50 & 0.64 & 3.26 & 1.06 & 1.76 & 1.75 & 1.01 & 1.85 & 0.43 & 0.10 \\
\hline 9 & $\begin{array}{l}\text { The procedure for cervical cancer } \\
\text { screening is painful }\end{array}$ & 1.59 & 0.65 & 3.17 & 0.99 & 1.58 & 2.24 & 1.11 & 1.77 & 0.55 & -0.47 \\
\hline 10 & $\begin{array}{l}\text { If I know my status of cervical } \\
\text { cancer I will die before time }\end{array}$ & 1.49 & 0.54 & 2.66 & 0.99 & 1.17 & 1.88 & 1.12 & 2.09 & 0.63 & 0.20 \\
\hline 11 & $\begin{array}{l}\text { I will be stigmatized by my spouse } \\
\text { if I test positive to cervical cancer }\end{array}$ & 1.56 & 0.67 & 2.84 & 0.95 & 1.28 & 1.66 & 0.98 & 2.04 & 0.60 & 0.38 \\
\hline 12 & $\begin{array}{l}\text { I will lose my virginity during } \\
\text { cervical cancer screening }\end{array}$ & 1.61 & 0.74 & 3.00 & 0.98 & 1.39 & 1.80 & 1.07 & 1.97 & 0.49 & 0.18 \\
\hline 13 & $\begin{array}{l}\text { The test of cervical cancer is } \\
\text { unnecessary and without benefit }\end{array}$ & 1.36 & 0.48 & 3.16 & 1.14 & 1.80 & 1.66 & 0.99 & 1.99 & 0.49 & 0.33 \\
\hline 14 & $\begin{array}{l}\text { Cervical cancer cannot be } \\
\text { prevented }\end{array}$ & 1.56 & 0.62 & 2.77 & 1.25 & 1.20 & 1.70 & 0.96 & 2.30 & 0.55 & 0.60 \\
\hline 15 & $\begin{array}{l}\text { Only the gods can prevent cervical } \\
\text { cancer }\end{array}$ & 1.83 & 1.09 & 2.32 & 1.30 & 0.50 & 1.81 & 1.16 & 1.76 & 0.92 & -0.04 \\
\hline 16 & $\begin{array}{l}\text { cervical cancer is the disease of the } \\
\text { illiterates }\end{array}$ & 1.39 & 0.70 & 2.64 & 1.23 & 1.25 & 1.86 & 1.07 & 1.97 & 1.01 & 0.12 \\
\hline \multirow[t]{2}{*}{17} & $\begin{array}{l}\text { Cervical cancer affect only married } \\
\text { women }\end{array}$ & 1.25 & 0.44 & 2.44 & 1.15 & 1.18 & 1.50 & 0.94 & 1.50 & 0.94 & 0.00 \\
\hline & Grand Mean & 1.57 & 0.22 & 2.83 & 0.55 & 1.26 & 1.79 & 0.77 & 1.75 & 0.27 & -0.05 \\
\hline
\end{tabular}

The result on Table 2 shows the summary of mean rating on attitude of the teachers toward cervical cancer screening in the experimental and control groups. Shows that the mean pretest attitude score of the experimental group was $1.57, \mathrm{SD}=0.22$ whereas their mean posttest attitude score was $2.83, \mathrm{SD}=0.55$ indicating an attitudinal gain of 1.26 . On the other hand the mean pretest attitude score of the control group was $1.79, \mathrm{SD}=0.77$ and their mean posttest attitude score was $1.75, \mathrm{SD}=0.27$ indicating an attitudinal loss of 0.05 . This reveals that IECbased intervention has effect of on attitude 
Fig. 4.6: Mean gain or loss in attitude towards cervical cancer screening within groups

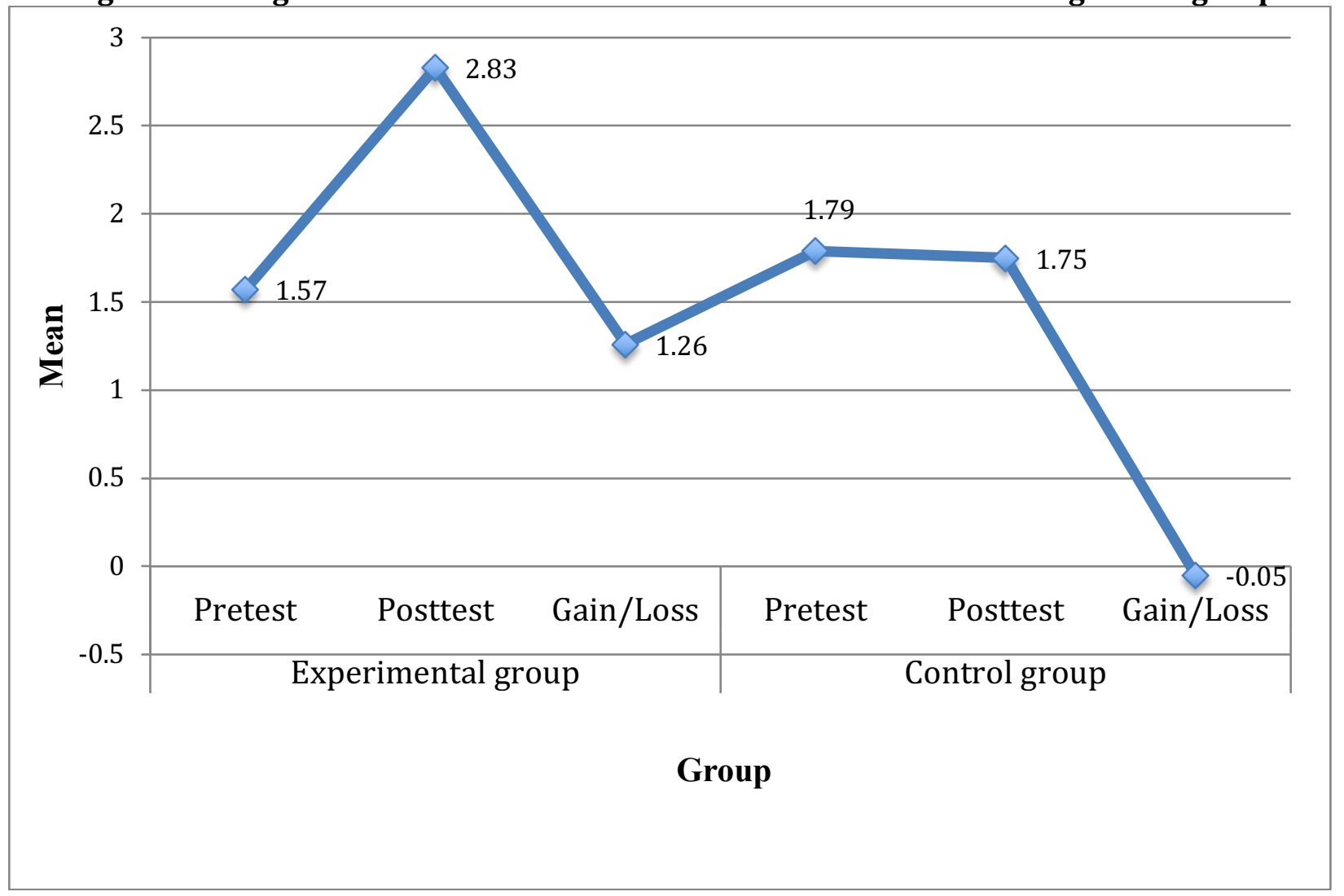

Hypothesis1: IEC-based intervention has no significant effect on knowledge of cervical cancer screening among teachers of Jalingo.

Table 3: Summary of Analysis of Covariance (ANCOVA) on the difference in the knowledge of cervical cancer prevention among teachers of Jalingo based on group.

\begin{tabular}{lcccccc}
\hline Source & $\begin{array}{c}\text { Type III Sum } \\
\text { of Squares }\end{array}$ & df & $\begin{array}{c}\text { Mean } \\
\text { Square }\end{array}$ & F & Sig. & $\begin{array}{c}\text { Partial Eta } \\
\text { Squared }\end{array}$ \\
\hline Corrected Model & $3186.238^{\mathrm{a}}$ & 2 & 1593.119 & 110.598 & .000 & .509 \\
Intercept & 3996.080 & 1 & 3996.080 & 277.416 & .000 & .566 \\
Pre-Knowledge & 567.319 & 1 & 567.319 & 39.385 & .000 & .156 \\
Treatment & 945.315 & 1 & 945.315 & 65.626 & .000 & .236 \\
Error & 3068.188 & 213 & 14.405 & & & \\
Total & 160602.000 & 216 & & & & \\
Corrected Total & 6254.426 & 215 & & & & \\
\hline
\end{tabular}

a. R Squared $=.509$ (Adjusted R Squared $=.505$ )

Table 3 shows the summary of Analysis of Covariance (ANCOVA) on the difference in the knowledge of cervical cancer prevention among teachers of Jalingo based on group. The results shows that IEC-based intervention has significant effect on knowledge of cervical cancer prevention among teachers of Jalingo with the calculated value of 65.626 at degree of freedom of 1 and 213 of .000 which is less than 0.05 (F1, 213=65.626, p<.05). Hence the null hypothesis one was rejected at .05 alpha levels. The Partial Eta Squared was found to be $57.4 \%$.

Hypothesis2: IEC-based intervention has no significant effect on the attitude of teachers towards cervical cancer prevention in Jalingo. 
Table 4: Summary of ANCOVA on the difference in the attitude towards cervical cancer prevention among teachers of Jalingo based on group.

\begin{tabular}{lcccccc}
\hline Source & $\begin{array}{c}\text { Type III Sum } \\
\text { of Squares }\end{array}$ & df & $\begin{array}{c}\text { Mean } \\
\text { Square }\end{array}$ & F & Sig. & $\begin{array}{c}\text { Partial Eta } \\
\text { Squared }\end{array}$ \\
\hline Corrected Model & $64.641^{\mathrm{a}}$ & 2 & 32.320 & 184.283 & .000 & .634 \\
Intercept & 92.124 & 1 & 92.124 & 525.268 & .000 & .711 \\
Pre-Attitude & 1.802 & 1 & 1.802 & 10.274 & .002 & .046 \\
Treatment & 64.606 & 1 & 64.606 & 368.367 & .000 & .634 \\
Error & 37.357 & 213 & .175 & & & \\
Total & 1206.644 & 216 & & & & \\
Corrected Total & 101.998 & 215 & & & & \\
\hline
\end{tabular}

a. R Squared $=.634$ (Adjusted R Squared $=.630$ )

The result from Table 4.9 indicates the summary of ANCOVA on the difference in the attitude towards cervical cancer screening among teachers of Jalingo based on group. It reveals that IEC-based intervention has significant effect on the attitude of teachers towards cervical cancer screening in the treatment group with F-value of 368.367 at degree of freedom of 1 and .000 level of significance less than $0.05 \quad(F 1,213=368.367, \mathrm{p}<.05)$. The null hypothesis two was rejected at .05 alpha levels. The Partial Eta Squared was found to be $63.34 \%$.

\section{DISCUSSION OF FINDINGS}

This study was carried out to determine the Effect of IEC- based intervention on knowledge, attitude toward cervical cancer prevention among female primary school teachers in Jalingo. The findings revealed that knowledge about the nature of cervical cancer prevention improved over time in both groups but with more improvement in the experimental group. It is worthy of note that there was an average percentage increase of $12.84 \%$ in true responses among teachers in the experimental group. At baseline the average percent of knowledge was $85.22 \%$. After exposure of the experimental group to treatment IEC-based intervention there was relative again in knowledge where only $1.94 \%$ till had low knowledge of CC prevention compared with the control group that at the baseline the average of $60.57 \%$ had knowledge of CC prevention and during the posttest $17.50 \%$ had no adequate knowledge of CCS. Also the findings of analysis of hypothesis one revealed that IEC-based intervention has significant effect on knowledge of cervical cancer screening among teachers (F1, 213=65.626, $\mathrm{p}<.05$ ). This is in line with the findings where IEC significantly improve the knowledge of household heads about community -based health insurance (CHI) and to an extent the effect was observed in household enrolment in the scheme (Cofie, De Allegri Kouyate \& Sauerborn 2013). Zaman, (2013).Carried out a study on Impact assessment of IEC intervention on knowledge attitude and practice (KAP) of HIV/AIDS in Assam. His findings agreed with the fact that IEC improves knowledge.

This suggest that IEC if integrated in health interventions will significantly improve knowledge since different IEC materials ranging from audio, visual to audio-visual are combine to pass health information and education with the expectation to facilitate assimilation of health information. Thus the more knowledge people acquired about cervical cancer, the likelihood they are to accept and practice the recommended behaviours in contrast to those who lack knowledge or adequate knowledge of the disease. Knowledge is imperative in prevention of CC; as earlier stated CC is a preventable cancer but require that women be empowered with adequate knowledge through IEC health education.

\section{EFFECT OF IEC- BASED INTERVENTION ON ATTITUDE OF PRIMARY SCHOOL TEACHERS TOWARD CERVICAL CANCER PREVENTION.}

The findings of the study showed that the mean pretest attitude score of the experimental group was $1.57, \mathrm{SD}=0.22$ whereas their mean posttest attitude score was $2.83, \mathrm{SD}=0.55$ 
indicating an attitudinal gain of 1.26. On the other hand the mean pretest attitude score of the control group was $1.79, \mathrm{SD}=0.77$ and their mean posttest attitude score was $1.75, \mathrm{SD}=0.27$ indicating an attitudinal loss of 0.05 . This justifies the efficacy of the IEC-based intervention at metamorphosing the attitudes of the teachers towards cervical cancer screening. When put to statistical test, the result on (Table 4.) shows that IEC-based intervention has significant effect on the attitude of teachers towards cervical cancer screening $(\mathrm{F} 1,213=368.367, \mathrm{p}<.05)$. The null hypothesis two was rejected at .05 alpha levels. The Partial Eta Squared was found to be 63.34\%. The findings above are in agreement with an earlier study by Adamu, Abiola \& Ibrahim (2012).which established that attitude of respondent in the intervention group improve significantly and higher than in the control group $(P<0.001)$.this findings shows that knowledge precede attitude.

That explains the improvement in the attitude of the respondents after exposure to cervical cancer IEC-based intervention. The researcher believes that IEC-based intervention if given will tremendously influence attitudes positively toward cervical cancer prevention. Thus the right information given to teachers will influence attitude and bring about a desire change in behaviour/ practice (Ezeruigbo, \& UdeNebonta, 2015). Unfortunately that was not the case with the control group as there was no exposure to IEC- based intervention to influence their attitude to bring about desire change in health behaviour. Invariable that may explains the increase in new diagnoses of cervical cancer since knowledge precede attitude and it is an influencer to behaviour change/practice.

\section{CONCLUSION}

Knowledge and attitude toward cervical cancer prevention significantly improved in the experimental group while minimal improvement was observed in the control group. Suggesting that reduction of morbidity and mortality rate depends on successful implementation of IEC-based intervention programmes. Therefore it is recommended that Periodic IEC-based seminars on cervical cancer should be organizing for teachers and they should be encouraged to step down the knowledge to the female's learner in order to retain knowledge and influence attitude and prevention practices. Nigerian Ministry of health should develop and implement policy for IEC-based health education on cervical cancer prevention to be given in all maternal and child health clinic on each visit. And cervical cancer screening should be part of the routine examination.

\section{References}

Abiodun 0., Fatungase, O. K., Olu-Abiodun, O., Idowu-Ajiboye, B. A. and Awosile J. 0. (2013). An Assessment of Women's Awareness Knowledge about Cervical Cancer and Screening and the Barriers to Cervical Screening in Ogun State, Nigeria. International Organization of Scientific Research Journal of Dental and Medical Science 10(3):52-58

AdamuA N, Abiola A 0, Ibrahim M. (2012).The effect of health education on the knowledge, attitude, and uptake of free Pap smear among female teachers in Birnin-Kebbi, North-Western Nigeria. Nigeria Journal of Clinical Practice;15:326-32

Akintayo, B. J., \& Bello, A. A., (2015).Creating Awareness on Cervical Cancer via Radio Broadcasting in Ikenne Local Government. New Media and Mass Communication. Retrieved from http://www.iiste.org ISSN 2224-3267 (Paper) ISSN 2224-3275.

Bethune, G. R, and Lewis, H. J.(2009). Let's talk about smear tests: Social marketing for the National Cervical Screening Programme. Public Health 123(e-Supplement): e17-22.

Cofie, De Allegri Kouyate and Sauerborn 2013).Effects of information, education, and communication campaign on a community-based health insurance scheme in Burkina Faso Global Health Action.6: doi:10.3402/gha.v6i0.20791.

Denny, L., Herrero, R., Levin, C., and Kim, J. J. (2015). Cervical: Disease Control priorities. Third Edition. 3 Retrieved from https://www.ncbi.nlm.nih.gov/books/NBK343648/ 
Ezeruigbo, C. R., and UdeNebonta, A. R .(2015). Impact of Health education on knowledge, attitude and practice of cervical cancer screening among Secondary School Teachers in Enugu State. Journal of women's Health care 4:241

Forouzanfar, M. M. H, Foreman, K. K. J., Delossantos, A. M., Lozano, R., Lopez, A. D., Murray, C. J., Naghavi, M. (2011). Breast and cervical cancer in 187 countries between 1980 and 2010: a systematic analysis. Lancet 378(9801):1461-1484. Retrieved from http://www.ncbi.nlm.nih.gov/pubmed/2192448610.1016/S0140-6736(11)61351-2

Gamage, D. (2017) Cervical cancer : preventable deaths of women to shape up the future Journal of the College of Community Physicians of Sri Lanka, 23 (4) DOI: https://doi.org/10.4038/jccpsl.v23i4.8133

Gatune J. W., and Nyamongo I. (2005). An ethnographic study of cervical cancer among women in rural Kenya: Is there a folk causal model? International Journal Gynaecological Cancer. 6: 1049-1059

GLOBOCAN (2012).Estimated cancer incidence, mortality and prevalence worldwide in 2012. France: International Agency for Research on Cancer, World Health Organization, 2013. Retrieved October 10th2019 from: http://globocan.iarc.fr/.

Hanisch, R., Gustat, J., Hagensee, M. E., Baena, A., Salazar, J. E., Castro, M. V., Gaviria, A. M., and Sanchez, G. I. (2008). Knowledge of Pap screening and human papillomavirus among women attending clinics in Medellín, Colombia. International Journal of Gynecological Cancer. 18: 1020-1026. Retrieved from https://www.ncbi.nlm.nih.gov/pubmed/18021221

Horo A., Jaquet A. Ekouevi D. K., et al (2012). The IeDEA West Africa collaboration. Cervical cancer screening by VIA CotedIvoire, operational \& Clinical aspects according to HIV status

Labonté, R, and Schrecker, T. (2007).Globalization and social determinants of health: The role of the global marketplace. Globalization and Health; 2007Retrieved July 10th 2019 from: http://www.globalizationand health.com/content/3/1/6

McGraw, S. L. and Ferrante, J. M. (2014). Update on Prevention and Screening of Cervical Cancer. World Journal of Clinical Oncology. 5(4):744-752. Retrieved June $12^{\text {th }} 2019$ from

https://www.ncbi.nlm.nih.gov/pmc/articles/PMC4129537/

Nwankwo, K. C. Aniebue, U. U. Aguwa, E. N.Anarado, A. N. Agunwah, E. (2011). Knowledge attitudes and practices of cervical cancer screening among urban and rural Nigerian women: a call for education and mass screening. European Journal of Cancer Care. 20 (3): 362-367

Nwankwo, K. C. Aniebue, U. U. Aguwa, E. N.Anarado, A. N. Agunwah, E. (2011). Knowledge attitudes and practices of cervical cancer screening among urban and rural Nigerian women: a call for education and mass screening. European Journal of Cancer Care. 20 (3): 362-367

Osumanu, I. K.(2008) R Thomas J, Ojemakinde O, Izebraye I. (2002). Current concepts in cervical carcinogenesis and new perspectives in prevention.Arch Ibadan Med.; 3(1): 36-9.

Sule A. A, Ochicha O. A (2017). histopathologic review of cervical cancer in Kano, Nigeria. Sahel Medical Journal;20:16-20

WHO (2013). Comprehensive cervical cancer prevention and control: a healthier future for girls and women, Geneva, Switzerland, 2013. Retrieved July 20th 2019 from https://www.ncbi.nlm.nih.gov/pmc/articles/PMC5526548\#pone.0181415.refo06

World Health Organization (2019).Cervical Cancer. Retrieved Sept.10 2019 from https://www.who.int/cancer/prevention/diagnosis-screenin

World Health Organization, (2014).Cancer country profiles. World Health Organization, Geneva.

World Health Organization.(2015). Cervical cancer - issues and challenges. Retrieved Sept.10 ${ }^{\text {th }} 2019$ from: http://www.afro.who.int/index:

World Health Organization: International Agency for research on cancer (2018). Press Release $\mathrm{N}^{\circ} 26312$ September 2018 Latest global cancer data: Cancer burden rises to 18.1 million new cases and 9.6 million cancer deaths in 2018

Zaman, F. A.(2013). Impact assessment of IEC intervention on knowledge attitude and practice (KAP) of HIV/AIDS in Assam. Annals of Tropical Medicine and Public Health; 6(6):44-8. 